
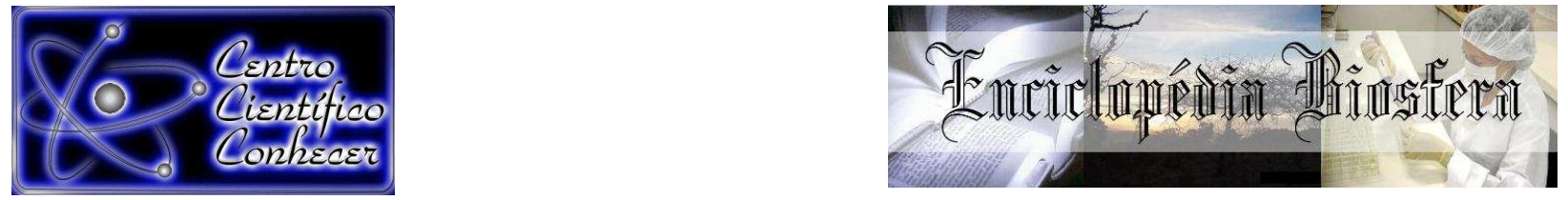

\title{
QUALIDADE FISIOLÓGICA DE SEMENTES DE BRACATINGA SUBMETIDAS À ASSEPSIA COM DIFERENTES AGENTES QUIIMICOS
}

\footnotetext{
Alexandre de Araújo Ascoli ${ }^{1}$, Flávio Ferreira da Silva Binotti ${ }^{2}$, Gabriel Wanderley de Mendonça $^{3}$, Eliana Duarte Cardoso ${ }^{4}$, Edilson Costa ${ }^{2}$

${ }^{1}$ Pós-graduando do Programa de Mestrado em Agronomia da Universidade Estadual do Mato Grosso do Sul, Campus Cassilândia, Mato Grosso do Sul, Brasil (aaascoli@yahoo.com.br)

${ }^{2}$ Prof. Doutor do Programa de Mestrado em Agronomia da Universidade Estadual do Mato Grosso do Sul, Campus Cassilândia, Mato Grosso do Sul, Brasil

${ }^{3}$ Pós-graduando do Programa de Mestrado em Agronomia da Universidade Estadual do Mato Grosso do Sul, Campus Cassilândia, Mato Grosso do Sul, Brasil

${ }^{4}$ Prof. ${ }^{a}$ Doutora do Curso de Agronomia da Universidade Estadual do Mato Grosso do Sul, Campus Cassilândia, Mato Grosso do Sul, Brasil
}

Recebido em: 03/10/2016 - Aprovado em: 21/11/2016 - Publicado em: 05/12/2016 DOI: 10.18677/EnciBio_2016B_085

\begin{abstract}
RESUMO
A bracatinga (Mimosa scabrella Bentham) é uma árvore nativa do sul do Brasil amplamente utilizada na construção de moradias e para a obtenção de carvão vegetal. O objetivo foi avaliar o efeito de diferentes agentes químicos e tempos de exposição, na assepsia superficial das sementes, sobre a qualidade fisiológica de sementes de bracatinga. Os tratamentos foram dispostos em delineamento inteiramente casualizado em esquema fatorial $4 \times 5$, com diferentes agentes químicos $\left(\mathrm{H}_{2} \mathrm{O}\right.$; Q-Boa ${ }^{\circledR} 35 \%$; Hipoclorito de sódio $9 \%$; Lysoform $\left.{ }^{\circledR} 9 \%\right)$ e cinco tempos de exposição $(0,5,10,15$ e 20 minutos), com quatro repetições. Parâmetros analisados: primeira contagem de germinação, germinação, sementes inviáveis, condutividade elétrica, emergência e comprimento radicular. A utilização de diferentes agentes químicos e tempos de exposição na assepsia de sementes de bracatinga, não afetaram a germinação das sementes, todavia o aumento da exposição aos agentes químicos afetou negativamente o vigor das sementes.
\end{abstract}

PALAVRAS-CHAVE: emergência, germinação, Mimosa scabrella Bentham.

\section{PHYSIOLOGICAL QUALITY OF BRACATINGA SEEDS SUBMITTED TO ASEPSIS WITH DIFFERENT CHEMICAL AGENTS}

\begin{abstract}
The bracatinga (Mimosa scabrella Bentham) is a tree native to southern Brazil widely used in housing construction and obtaining charcoal. The objective was to evaluate the effect of different chemical agents and exposure times, in the superficial asepsis of seeds, about physiological quality of bracatinga seeds. The treatments were arranged in a randomized design in a factorial $4 \times 5$, with different chemical agents $\left(\mathrm{H}_{2} \mathrm{O}\right.$; Q-Boa ${ }^{\circledR} 35 \%$; Hypochlorite sodium $9 \%$; Lysoform $\left.{ }^{\circledR} 9 \%\right)$ and five exposure times $(0,5,10,15$ and 20 minutes), with four replicates. Parameters analyzed: first germination count, germination, unviable seeds, electrical conductivity, emergence and root length. The use of different chemical agents and exposure times in the
\end{abstract}


asepsis of bracatinga seeds, did not affect seed germination, however the increased exposure to chemicals agents negatively affected the seed vigor.

KEYWORDS: emergence, germination, Mimosa scabrella Bentham.

\section{INTRODUÇÃO}

A bracatinga (Mimosa scabrella Bentham) é uma árvore nativa do sul do Brasil que pertence à família Fabaceae e a subfamília Mimosoideae, ocorrendo desde Minas Gerais até o Rio Grande do Sul, sendo muito utilizada na forma de lenha e carvão, na construção civil, na confecção de móveis e na recuperação de áreas degradadas (ROSA et al., 2012).

A utilização de sementes de bracatinga com sanidade adequada é fundamental para se obter melhores níveis de germinação, sendo que FERRAZ \& CALVI (2010) indicam que o potencial germinativo das sementes pode ser afetado pela presença de microorganismos. Na maior parte das espécies florestais a propagação ocorre via sementes, assim a qualidade sanitária das sementes é essencial para a produção de mudas sadias (FANTINEL et al., 2013).

A utilização de agentes químicos na assepsia superficial de sementes contribui para o controle de organismos patogênicos (AMORIM et al., 2011), ocorrendo ampla variabilidade quanto ao uso do agente químico e o tempo de exposição empregado.

A utilização de diferentes produtos químicos para assepsia pode proporcionar sementes com diferentes níveis de germinação, dependendo do agente químico empregado e do tempo de exposição das sementes, sendo que as implicações tóxicas e a segurança ambiental devem ser sempre observadas (NWOKOCHA et al., 2015).

O objetivo foi avaliar o efeito de diferentes agentes químicos e tempos de exposição, sobre a qualidade fisiológica e assepsia superficial de sementes de bracatinga (Mimosa scabrella Bentham).

\section{MATERIAL E MÉTODOS}

Os experimentos foram conduzidos no Laboratório de Análise de Sementes, da Universidade Estadual de Mato Grosso do Sul - UEMS, Unidade Universitária de Cassilândia, localizada a altitude de 516 m, longitude de 514'15" W e latitude de 1907'21" S (Estação automática CASSILANDIA-A742), no município de Cassilândia - MS, durante os meses de julho a novembro de 2014. Foram utilizadas sementes de Mimosa scabrella, cuja qualidade fisiológica e viabilidade foram previamente avaliadas (Tabela 1).

TABELA 1 - Qualidade fisiológica de sementes de Mimosa scabrella. Cassilândia, MS (2014)

\begin{tabular}{ccccc}
\hline $\begin{array}{c}\text { Grau de umidade } \\
\text { das sementes }\end{array}$ & $\begin{array}{c}1^{\text {a }} \text { contagem de } \\
\text { germinação }\end{array}$ & $\begin{array}{c}\text { Germinação } \\
\text { total }\end{array}$ & $\begin{array}{c}\text { Sementes } \\
\text { inviáveis }\end{array}$ & IVG $^{*}$ \\
\hline 12 & 76 & 76 & 24 & 11,78 \\
\hline
\end{tabular}

İndice de velocidade de germinação

O delineamento experimental foi inteiramente casualizado em esquema fatorial $4 \times 5$, adotando-se quatro repetições por tratamento. O experimento foi composto por quatro agentes químicos diferentes para a exposição das sementes: $\mathrm{H}_{2} \mathrm{O}$ - controle; Q-Boa ${ }^{\circledR}(2,0 \%$ a $2,5 \%$ de cloro ativo, hidróxido de sódio, cloreto de 
sódio e água) a 35\%; Hipoclorito de sódio (10\% a $12 \%$ de cloro ativo) a 9\%; Lysoform $^{\circledR}$ (solução bactericida que contém soluto de formaldeído, cloreto bencilamônico de lauril-dimetilo, álcool etílico oficinal, essência de eucalipto citriodora e água depurada) a 9\% e cinco tempos de exposição: 0 (testemunha), 5, 10, 15 e 20 minutos.

Para se obter a concentração pré-estabelecida dos agentes químicos Q-Boa ${ }^{\circledR}$, hipoclorito de sódio e Lysoform ${ }^{\circledR}$, os mesmos foram diluídos com água deionizada, utilizando-se uma proveta de $100 \mathrm{~mL}$. Para a Q-boa ${ }^{\circledR}$ foi colocado $35 \mathrm{~mL}$ de Q-boa ${ }^{\circledR}$ e $65 \mathrm{~mL}$ de água. Para o Hipoclorito de sódio e o lysoform ${ }^{\circledR}$, foi colocado $9 \mathrm{~mL}$ do agente químico e $91 \mathrm{~mL}$ de água. Para cada tempo de exposição, foi utilizado um recipiente (Becker), que recebeu as 200 sementes de cada tratamento e posteriormente os $100 \mathrm{~mL}$ de água ou solução. Os tempos de exposição foram cronometrados com a utilização de um cronômetro com alarme. Após o término de cada tempo de exposição pré-estabelecido, as sementes foram colocadas em peneiras e expostas a água corrente por 1 minuto, sendo em seguida dispostas sobre papel toalha para secagem. Após a exposição, as sementes foram escarificadas mecanicamente com a utilização de uma Lixa Norton no 150 . Cada semente foi lixada somente no lado oposto ao embrião. Tal cuidado se fez necessário para que não houvesse danos a estrutura do embrião.

\section{Parâmetros analisados:}

Primeira contagem de germinação - Realizada juntamente com o teste de germinação, sendo que o registro foi verificado aos 7 dias após a instalação do teste.

Teste de germinação - Foi realizado com 4 sub-amostras de 50 sementes, sendo que as contagens foram efetuadas aos 7 e 14 dias após a semeadura.

Viabilidade das sementes remanescentes do teste de germinação Realizado através do teste de tetrazólio, utilizando as sementes remanescentes do teste de germinação (BRASIL, 2009). Para a execução do teste utilizou-se a concentração da solução de tetrazólio a $0,5 \%$, por um intervalo de tempo de 2 horas e a temperatura de $30^{\circ} \mathrm{C}$.

Condutividade elétrica - Para avaliação da condutividade elétrica da solução de embebição das sementes, utilizou-se o método conhecido como "condutividade de massa" ou sistema de copo. Para cada tratamento empregou-se quatro subamostras de 25 sementes. Em cada sub-amostra (repetição), mensurou-se a massa das 25 sementes com precisão de duas casas decimais. Em seguida, as sementes de cada repetição foram colocadas para embeber em um recipiente contendo $75 \mathrm{~mL}$ de água deionizada (3-5 $\mu \mathrm{S} \mathrm{cm}^{-1}$ de condutividade). Posteriormente, os recipientes foram acondicionados em BOD e mantidos durante um período de 24 horas à temperatura de $25^{\circ} \mathrm{C}$. Após o período de 24 horas foi feita a leitura da condutividade elétrica na solução de embebição, utilizando-se um condutivímetro. Os resultados foram expressos em $\mu S \mathrm{~cm}^{-1} \mathrm{~g}^{-1}$ de sementes (adaptado VIEIRA \& KRZYZANOWSKI, 1999).

Teste de emergência - Foi conduzido em casa de vegetação, empregandose quatro sub-amostras de 50 sementes por tratamento. A semeadura foi realizada em bandejas alveoladas de plástico (uma bandeja para cada tratamento). Em cada bandeja foram semeadas quatro linhas com 50 sementes a uma profundidade de 1 cm (cada linha consistia em uma repetição). Utilizou-se como substrato areia grossa peneirada. Registrou-se a porcentagem de plântulas emergidas até a estabilização da emergência, que ocorreu aos 20 dias após a semeadura. Consideraram-se como 
plântulas emergidas as que apresentaram comprimento da parte aérea não inferior a $20 \mathrm{~mm}$. Os resultados foram expressos em porcentagem de plântulas emergidas.

Comprimento radicular - Aos 20 dias mensurou-se o comprimento da parte radicular das plântulas (plântulas do teste de emergência), com uma régua graduada em $\mathrm{mm}$. Os valores foram expressos em $\mathrm{cm}$ por plântula.

Os dados, foram avaliados por meio da análise de variância pelo teste $\mathrm{F}$. Quando significativo ao nível de $5 \%$ de probabilidade, aplicou-se o teste de Tukey para o fator tipo de agente químico e se verificou ajuste a regressão polinomial para tempo de imersão; foi utilizado o programa SANEST (ZONTA \& MACHADO, 1986).

\section{RESULTADOS E DISCUSSÃO}

Em relação aos fatores agentes químicos e tempo de exposição não foram verificadas interações para primeira contagem de germinação, germinação, sementes inviáveis, comprimento radicular e condutividade elétrica, sendo que as mesmas foram apresentadas isoladamente (Tabelas 2 e 3). Sementes de bracatinga expostas em soluções compostas pelos diferentes tratamentos estudados (produtos e exposição) não influenciaram a primeira contagem de germinação, germinação e sementes inviáveis (Tabela 2). Resultados que estão em concordância aos obtidos por SOUZA et al. (2011), em sementes de guabijuzeiro (Myrcianthes pungens (Berg) Legr.), onde os autores observaram que a desinfestação das sementes com solução de hipoclorito de sódio de 4 a $6 \%$ de cloro ativo não interferiu negativamente na germinação.

Sementes de bracatinga em solução com Lysoform ${ }^{\circledR}$ proporcionaram plântulas com comprimento radicular semelhante às plântulas oriundas de sementes com Hipoclorito de sódio e superior às plântulas provenientes de sementes com Q-Boa ${ }^{\circledR}$ e controle, todavia o aumento de exposição proporcionou queda no comprimento radicular do vegetal (Tabela 3). Resultados semelhantes aos obtidos por SILVA et al. (2015), onde os autores verificaram que em plântulas de murici-pequeno (Byrsonima intermedia A. Juss.), o aumento no tempo de exposição das sementes ao hipoclorito de sódio proporcionou efeitos nocivos ao sistema radicular das plântulas, promovendo redução no número de raízes. A condutividade elétrica em sementes de bracatinga aumentou proporcionalmente ao tempo de exposição das sementes nas soluções.

TABELA 2 - Primeira contagem de germinação, germinação e sementes inviáveis em função dos agentes químicos e do tempo de exposição em sementes de Bracatinga. UEMS, Cassilândia (MS), 2014

\begin{tabular}{lccc}
\hline \multicolumn{1}{c}{ Tratamentos } & $\begin{array}{c}1^{\text {a }} \text { contagem de } \\
\text { germinação } \\
(\%)\end{array}$ & $\begin{array}{c}\text { Germinação } \\
(\%)\end{array}$ & $\begin{array}{l}\text { Inviáveis } \\
(\%)\end{array}$ \\
\hline $\begin{array}{l}\text { Agentes químicos } \\
\text { Controle }\end{array}$ & $76 \mathrm{a}$ & $77 \mathrm{a}$ & $23 \mathrm{a}$ \\
Hipoclorito de sódio $_{\text {Lysoform }^{\circledR}}$ & $77 \mathrm{a}$ & $77 \mathrm{a}$ & $23 \mathrm{a}$ \\
Q-Boa $^{\circledR}$ & $78 \mathrm{a}$ & $78 \mathrm{a}$ & $21 \mathrm{a}$ \\
Tempo de exposição (minutos) $^{(}$ & $81 \mathrm{a}$ & $81 \mathrm{a}$ & $18 \mathrm{a}$ \\
0 & 80 & & \\
5 & 78 & 80 & 20 \\
10 & 76 & 79 & 21 \\
15 & 79 & 76 & 23 \\
20 & 78 & 79 & 21 \\
\hline F & $2,0786^{\text {N.S. }}$ & 78 & 21 \\
\hline
\end{tabular}

ENCICLOPÉDIA BIOSFERA, Centro Científico Conhecer - Goiânia, v.13 n.24; p. 901 2016 


\begin{tabular}{lccc}
\hline & $0,6993^{\text {N.S. }}$ & $0,5655^{\text {N.S. }}$ & $0,5530^{\text {N.S. }}$ \\
\hline C.V.(\%) & 8,34 & 8,43 & 16,78
\end{tabular}

${ }^{M}$ Médias seguidas de letras diferentes nas colunas dentro do fator agentes químicos, diferem entre $\mathrm{si}$ pelo teste Tukey a $5 \%$ de probabilidade; N.S. Não significativo.

TABELA 3 - Comprimento radicular e condutividade elétrica em função dos agentes químicos e do tempo de exposição em sementes de Bracatinga. UEMS, Cassilândia (MS), 2014

\begin{tabular}{|c|c|c|}
\hline \multirow[b]{2}{*}{ Tratamentos } & & Condutividade \\
\hline & Radicular (cm) & $\begin{array}{l}\text { Elétrica } \\
\left.\qquad \mathrm{cm}^{-1} \mathrm{~g}^{-1}\right)\end{array}$ \\
\hline \multicolumn{3}{|l|}{ Agentes químicos } \\
\hline Controle & $5,11 \mathrm{c}$ & $147,52 \mathrm{a}$ \\
\hline Hipoclorito de sódio & $5,74 a b$ & $160,39 \mathrm{a}$ \\
\hline Lysoform $^{\circledR}$ & $6,08 \mathrm{a}$ & $145,13 \mathrm{a}$ \\
\hline Q-Boa ${ }^{\circledR}$ & $5,49 \mathrm{bc}$ & $169,60 \mathrm{a}$ \\
\hline \multicolumn{3}{|c|}{ Tempo de exposição (minutos) } \\
\hline 0 & $5,77^{1}$ & $142,78^{2}$ \\
\hline 5 & 5,69 & 149,22 \\
\hline 10 & 5,60 & 155,66 \\
\hline 15 & 5,52 & 162,10 \\
\hline 20 & 5,43 & 168,54 \\
\hline \multirow{2}{*}{$\mathrm{F}$} & $15,7156^{* *}$ & $2,6364^{*}$ \\
\hline & R.L.* & R.L.* \\
\hline C.V.(\%) & 8,28 & 20,27 \\
\hline
\end{tabular}

${ }^{m}$ Médias seguidas de letras diferentes nas colunas dentro do fator agentes químicos, diferem entre si pelo teste Tukey a $5 \%$ de probabilidade; "significativo ao nível de $5 \%$ de probabilidade; R.L. = Regressão Linear; $y^{1}=-0,0170250 X+5,773875 ; y^{2}=1,2878137 X+142,783427$.

Sementes de bracatinga expostas por vinte minutos em solução de Q-Boa ${ }^{\circledR}$ proporcionaram menor emergência de plântulas provenientes (Tabela 4). Utilizando a Q-Boa ${ }^{\circledR}$ como agente químico, o aumento do tempo de exposição acarretou queda no percentual de emergência de plântulas.

TABELA 4 - Desdobramento da interação referente ao teste de emergência em função de diferentes agentes químicos e tempo de exposição em sementes de Bracatinga. UEMS, Cassilândia (MS), 2014

\begin{tabular}{lcccc}
\hline \multirow{2}{*}{ Tratamento } & \multicolumn{4}{c}{ Agentes químicos } \\
\cline { 2 - 5 } & Controle & Hip. sód. & Lysoform ${ }^{\circledR}$ & Q-Boa $^{\circledR}$ \\
\hline Tempo de exposição & $60 \mathrm{a}$ & $62 \mathrm{a}$ & $64 \mathrm{a}$ & $70 \mathrm{a}^{1}$ \\
\hline 0 & $49 \mathrm{~b}$ & $65 \mathrm{ab}$ & $66 \mathrm{ab}$ & $69 \mathrm{a}$ \\
5 & $57 \mathrm{a}$ & $70 \mathrm{a}$ & $68 \mathrm{a}$ & $58 \mathrm{a}$ \\
10 & $62 \mathrm{a}$ & $63 \mathrm{a}$ & $76 \mathrm{a}$ & $65 \mathrm{a}$ \\
15 & $68 \mathrm{a}$ & $67 \mathrm{a}$ & $71 \mathrm{a}$ & $37 \mathrm{~b}$ \\
20 & N.S. & N.S. & N.S. & R.Q. \\
\hline Regressão & & & & \\
\hline
\end{tabular}

C.V.(\%) 14,69

"Médias seguidas de letras minúsculas diferentes nas linhas dentro do fator agentes químicos, diferem entre si pelo teste Tukey a $5 \%$ de probabilidade; N.S. Não significativo; 'significativo ao nível de $5 \%$ de probabilidade; R.Q. = Regressão Quadrática; $y^{1}=-0,10142857 X^{2}+0,6385714 X+$ $68,528571, R^{2}=0,7852$. 
OLIVEIRA et al. (2012) avaliaram a influência da assepsia das sementes sobre o teste de sanidade, emergência e desenvolvimento de plântulas de Schizolobium amazonicum, onde observaram que a assepsia prévia das sementes com hipoclorito de sódio a 1,5\% por cinco minutos não influenciou à emergência das plântulas, sendo benéfico ao estabelecimento das mudas.

\section{CONCLUSÃO}

A utilização de diferentes agentes químicos e tempos de exposição na assepsia de sementes de bracatinga, não afetaram a germinação das sementes. $O$ vigor das sementes é afetado negativamente pelo aumento da exposição das sementes aos agentes químicos.

\section{REFERÊNCIAS}

AMORIM, L.; REZENDE, J. A. M.; BERGAMIN FILHO, A. Manual de Fitopatologia. São Paulo-SP: CERES, 2011. 704 p.

BRASIL. Ministério da Agricultura, Pecuária e Abastecimento/Secretaria de Defesa Agropecuária. Regras para análise de sementes. Brasília-DF: Mapa/ACS, 2009. $395 \mathrm{p}$.

FANTINEL, V. S.; OLIVEIRA, L. M.; MUNIZ, M. F. B.; ROCHA, E. C. Detecção de fungos e transmissão de alternaria alternata via sementes de ipê-amarelo, handroanthus chrysotrichus (mart. ex dc) Mattos. Revista de Ciências Ambientais, v. 7, n. 2, p. 05-14. 2013. Disponível em: <http://www.revistas.unilasalle.edu.br/index.php/Rbca>.

FERRAZ, I. D. K.; CALVI, G. P. Teste de germinação. In: LIMA JUNIOR, M. J. V. Manual de procedimentos de análise de sementes florestais. Manaus-AM: UFAM - Universidade Federal do Amazonas, cap. 5, p. 1-16. 2010.

NWOKOCHA, N. J.; UMECHURUBA, C. I.; WOKOCHA, R. C.; OPARA, E. U.; NWOKOCHA, J. V. Reduction of seed-borne fungi of the genus Aspergillus associated with egusi melon Colocynthis citrullus (L.) seeds using chlorine disinfectants - implications on seed germination. Journal of Agriculture and Sustainability, $\quad$ v. $7, \quad$ n. 1, p. 87-98. 2015. Disponível em: <http://infinitypress.info/index.php/jas/article/view/1080/483>.

OLIVEIRA, J. D.; SILVA, J. B.; DAPONT, E. C.; SOUZA, L. M. S.; RIBEIRO, S. A. L. Métodos para detecção de fungos e assepsia de sementes de Schizolobium amazonicum (Caesalpinioideae). Bioscience Journal, v. 28, n. 6, p. 945-953. 2012. Disponívelem:<http://www.seer.ufu.br/index.php/biosciencejournal/article/view/13938 /11105>.

ROSA, F. C.; REINIGER, L. R. S.; GOLLE, D. P.; MUNIZ, M. F. B.; CURTI, A. R. Superação da dormência e germinação in vitro de sementes de bracatinga (Mimosa scabrella Bentham). Semina: Ciências Agrárias, v. 33, n. 3, p. 1021-1026. 2012. Disponível em: <http://dx.doi.org/10.5433/1679-0359.2012v33n3p1021>. doi: 10.5433/1679-0359.2012v33n3p1021 
SILVA, L. C.; PAIVA, R.; VARGAS, D. P.; SILVA, D. P. C.; BARBOSA, S.; HERRERA, R. C. Decontaminant solution on in vitro growth of Byrsonima intermedia seedlings. Ciência Rural, v. 45, n. 4, p. 674-679. 2015. Disponível em: < http://dx.doi.org/10.1590/0103-8478cr20120078>.doi:10.1590/0103-8478cr20120078

SOUZA, L. S.; FIOR, C. S.; SOUZA, P. V. D.; SCHWARZ, S. F. Desinfestação de sementes e multiplicação in vitro de guabijuzeiro a partir de segmentos apicais juvenis (myrcianthes pungens O.Berg) D. Legrand. Revista Brasileira de fruticultura, v. 33, n. 3, p. 691-697. 2011. Disponível em: <http://dx.doi.org/10.1590/S0100-29452011005000081>. doi: 10.1590/S010029452011005000081

VIERA, R. D.; KRYZANOWSKI, F. C. Teste de condutividade elétrica. In: KRYZANOWSKI, F. C.; VIEIRA, R. D.; FRANÇA NETO, J. B. Vigor de sementes: conceitos e testes. Londrina-PR: ABRATES, cap. 4, p. 1-24. 1999.

ZONTA, E. P.; MACHADO, A. A. Sistema de Análise Estatística para microcomputadores - SANEST. Pelotas-RS: UFPel, Instituto de Física e matemática, 1986. $150 \mathrm{p}$. 